\title{
Qualidade do leite cru refrigerado obtido em unidades produtivas no Sudoeste do Paraná
}

\author{
Quality of refrigerated raw milk obtained in production units in southwest Paraná
}

\section{Claudinei Zucco Pitro Belli, Jacson Rodrigo Cullmann*, Magnos Fernando Ziech, Luis Fernando Glasenapp de Menezes e Fernando Kuss}

Recebido em 25/11/2015 / Aceito em 29/11/2016

\section{RESUMO}

A qualidade do leite é um dos temas mais discutidos atualmente no cenário nacional de produção leiteira. Desta forma, o objetivo deste trabalho foi avaliar os parâmetros qualitativos e disponibilizar informações referentes aos fatores que possam interferir na qualidade do leite cru refrigerado obtido mensalmente em 40 unidades produtoras de seis municípios na região Sudoeste do Paraná. Foi realizada a coleta de dados das propriedades com o auxílio de um questionário semiestruturado. Consideraram-se 12 parâmetros inerentes à atividade leiteira e que podem influenciar na qualidade da matéria-prima, conforme segue: estrato de produção, sistemas de produção, de ordenha, de resfriamento, mão de obra, assistência técnica, frequência da assistência, higienização do resfriador, da ordenha, dos tetos, desinfecção dos tetos e estrutura do ambiente de ordenha. As amostras de leite foram analisadas em relação a sua composição: gordura, proteína, lactose e Extrato Seco Total (EST), a Contagem de Células Somáticas (CCS) e Contagem Padrão em Placas (CPP). A proteína e CCS não foram influenciadas por nenhum dos parâmetros estudados. O teor de gordura é um dos componentes do leite mais passiveis a apresentar variação na proporção, o qual foi influenciado pelo estrato de produção, tipo de mão de obra, frequência da assistência técnica, higienização do resfriador e tipo de contenção disponível na propriedade. As variáveis que apresentaram maiores valores para gordura e CPP estão associados a propriedades com nível tecnológico e produção inferiores. Aspectos nutricionais que promovem o aumento da produção, como identificado nos sistemas de maior produção de leite resultam em menor percentual de gordura do leite. Instalações que apresentam a ordenha canalizada e resfriamento por expansão proporcionam melhores resultados para CPP. Práticas como o uso de pré e pós-dipping, higienização do resfriador e ordenhadeira com água quente e detergente reduz significativamente a CPP.

PALAVRAS-CHAVE: células somáticas, composição físico química, gordura, produção leiteira, proteína, Instrução Normativa 62, microrganismos

\section{ABSTRACT}

The quality of milk is one of the most widely discussed topics in the national dairy production scenario. Thus, the objective of this study was to evaluate the qualitative parameters and provide information regarding the factors that can affect the quality of refrigerated raw milk obtained monthly in 40 production units in six municipalities in Paraná Southwest region. Data collection was carried out of the properties with the aid of a semi-structured questionnaire. Twelve parameters were considered inherent in dairy farming and that can influence the quality of the raw material, as follows: production stratum, production systems, milking, cooling, labor, and service, frequency of care, hygiene of cooler, the milking teat disinfection ceilings and structure of the milking environment. The milk samples were analyzed for their composition of: fat, protein, lactose and Dry Total Extract (DTE), the Somatic Cell Count (SCC) and Count Standard on plates (CSP). The protein and SCC were not influenced by any of the parameters studied. The fat content is one of the milk components most likely to introduce variation in the ratio, which was influenced by the production stratum, type of labor, frequency of service, cooler cleaning and type of containment available on the property. The variables that showed higher values for fat and CSP are associated with properties with technological level and lower production. Nutritional aspects

Universidade Tecnológica Federal do Paraná, Dois Vizinhos, PR, Brasil.

*Autor para correspondência <jrcullmann@gmail.com> 
that promote increased production, as identified in the higher milk production systems result in lower percentage of milk fat. Facilities that have channeled milking and cooling by expansion provide better results for CSP. Practices such as the use of pre and post-dipping, cooler cleaning and milking machine with hot water and detergent significantly reduce the CSP.

KEYWORDS: somatic cells, chemical physical composition, fat, milk production, protein, Instruction 62 , microorganisms.

\section{INTRODUÇÃO}

A pecuária leiteira ocupa papel importante na agropecuária brasileira, envolve grande número de agricultores no processo produtivo e apresenta significativa capacidade de geração de empregos, trabalho e renda, desde as atividades produtivas até a industrialização dos produtos, com capacidade de gerar um fluxo rápido de capital, o que define a pecuária leiteira como fundamental na manutenção da estrutura produtiva familiar, principalmente pela questão da renda constante (ALEIXO et al. 2007).

A qualidade do leite é um dos temas mais discutidos atualmente dentro do cenário nacional de produção leiteira. A identificação dos pontos críticos, a adoção de técnicas profiláticas de manejo e o investimento em novas tecnologias nas diversas etapas do processo produtivo podem contribuir significativamente para obtenção de leite que atenda aos parâmetros qualitativos estabelecidos pela legislação.

A contaminação microbiana sofre influência de diversos fatores, desde a saúde da glândula mamária, a higiene de ordenha, o ambiente em que a vaca fica alojada, qualidade da água utilizada, até a temperatura e tempo de armazenagem do leite (SANTOS \& FONSECA 2007). Além da Contagem Padrão em Placas (CPP), a Contagem Células Somáticas (CCS), outras análises físico-químicas são fundamentais para o processo de controle da qualidade do leite cru, sabendo que este é a base de toda a cadeia láctea, e a má qualidade da matéria prima pode afetar a fabricação dos derivados (BELOTI et al. 2011).

$\mathrm{O}$ Ministério da Agricultura, Pecuária e Abastecimento (MAPA) estabeleceu por meio da Instrução Normativa 51 de 18/09/2002 (BRASIL 2002), Regulamentos Técnicos de Produção,
Identidade e Qualidade do Leite tipo A, do Leite tipo B, do Leite tipo C, do Leite Pasteurizado e do Leite Cru Refrigerado e o Regulamento Técnico da Coleta de Leite Cru Refrigerado e seu Transporte a Granel. A partir de então, para fins de monitoramento da qualidade, as análises para os requisitos químicos, físicos, microbiológicos, CCS e de resíduos químicos passaram a ser realizadas pela Rede Brasileira de Laboratórios de Controle da Qualidade do Leite. Posteriormente, em dezembro de 2011, a IN 51 foi complementada pela IN 62 (BRASIL 2011), a qual estabeleceu novos requisitos para CCS e CPP e passou a vigorar a partir de 01 de janeiro de 2012 (Tabela 1), pois os produtores não conseguiram se adaptar ao que a legislação exigia no tempo previsto.

O objetivo deste trabalho foi avaliar os parâmetros qualitativos e disponibilizar informações referentes aos fatores que possam interferir na qualidade do leite cru refrigerado obtido mensalmente em 40 unidades produtoras de seis municípios na região Sudoeste do Paraná.

\section{MATERIAL E MÉTODOS}

O estudo foi conduzido em parceria com o Departamento de fomento de uma unidade de captação de leite (Cooperativa), na região Sudoeste do Paraná. O período experimental teve início no mês de julho de 2012 e término em junho de 2014. Foram sorteadas 60 unidades de produção leiteira, sendo que no decorrer deste período 20 estabelecimentos passaram a entregar a produção para outra empresa, restando ao final, os dados de 40 propriedades para avaliação. As unidades produtoras estudadas localizavam-se em seis municípios da região Sudoeste, conforme segue: São João (10), Chopinzinho (5), Mangueirinha (6), Sulina (10), Coronel Vivida (4) e São Jorge D’Oeste (5).

Após determinadas às propriedades, elaborouse um questionário estabelecendo as variáveis (independentes) para estudo em cada estabelecimento produtivo, o qual foi aplicado no início e no final do período de avaliação, a fim de identificar e excluir os estabelecimentos que diferiram do último para o primeiro questionário para alguma das variáveis préestabelecidas, de modo que os dados qualitativos das 40 unidades produtivas proporcionassem o estudo das 12 variáveis. Consideraram-se doze parâmetros inerentes à atividade leiteira e que poderiam influenciar a qualidade do leite, conforme segue: 
Tabela 1 - Requisitos físico-químicos, microbiológicos e de Contagem de Células Somáticas para o leite cru refrigerado, segundo a IN 51 de 18/09/2002 e IN 62 de 29/12/2011 do Ministério da Agricultura, Pecuária e Abastecimento, avaliados pela Rede Brasileira de Laboratórios de Controle da Qualidade do Leite para a região Sul, Sudeste e Centro-Oeste do Brasil.

Table 1 - Physical-chemical requirements, microbiological and Somatic Cell Count for refrigerated raw milk, according to IN 51 of 18/09/2002 and 29/12/2011 IN 62 of the Ministério da Agricultura, Pecuária e Abastecimento, evaluated by the Rede Brasileira de Laboratórios de Controle da Qualidade do Leite for the South, Southeast and Midwest of Brazil.

\begin{tabular}{lc}
\hline Requisito & Limites \\
\hline Matéria gorda $(\mathrm{g} / 100 \mathrm{~g}$, mínimo) & 3 \\
Densidade relativa a $15^{\circ} \mathrm{C}(\mathrm{g} / \mathrm{mL})$ & $1,028 \mathrm{a} 1,034$ \\
Acidez titulável $(\mathrm{g}$ ácido lático $/ 100 \mathrm{~mL})$ & $0,14 \mathrm{a} 0,18$ \\
Extrato seco desengordurado $(\mathrm{g} / 100 \mathrm{~g}$, mínimo) & 8,4 \\
Índice Crioscópico & $-0,530^{\circ} \mathrm{H}$ a $-0,550^{\circ} \mathrm{H}$ \\
Proté́nas $(\mathrm{g} / 100 \mathrm{~g}$ mín.) & 2,9 \\
Contagem Padrão em Placas $(\mathrm{UFC} / \mathrm{mL}$, máximo) & $600 \times 10^{3}$ \\
Contagem de Células Somáticas $(\mathrm{CS} / \mathrm{mL}$, máximo) & $600 \times 10^{3}$ \\
\hline
\end{tabular}

Fonte: (BRASIL 2002, 2011).

estrato de produção mensal (até 6.000 , de 6.001 a 12.000, acima de 12.000 litros), sistema de produção (misto, confinado), sistema de ordenha (manual, mecanizada balde ao pé, mecanizada canalizada), sistema de resfriamento (imersão, expansão), mão de obra (familiar, contratada), assistência técnica (recebe, não recebe), frequência da assistência (mensal, eventual), higienização do refrigerador (água fria e detergente, água quente e detergente), higienização da ordenhadeira (água fria e detergente, água quente e detergente), higienização dos tetos (água, água e papel toalha, água e pano), desinfecção dos tetos (pré e pós dipping, pós dipping, não faz) e estrutura do ambiente de ordenha (contenção de ferro e piso de alvenaria, contenção de madeira e piso de alvenaria, contenção de madeira e piso de chão batido).

Realizaram-se coletas mensais de amostras do leite, direto do tanque de refrigeração durante a captação de rotina na unidade produtora, efetuada a cada 48 horas. Como primeiro critério, verificavase a temperatura do leite por meio de termômetro e realizava-se o teste do alizarol, o qual se baseia na ocorrência de coagulação por efeito da elevada acidez ou do desequilíbrio salino, quando se promove desestabilização das micelas pelo álcool. O alizarol, pela presença da alizarina, atua como indicador de $\mathrm{pH}$, auxiliando na diferenciação entre o desequilíbrio salino e a acidez excessiva (BRASIL 2006). Os agentes envolvidos na coleta do leite (transportadores) foram treinados pelo departamento de fomento, sobre os procedimentos para coleta das amostras, como a homogeneização do leite, manuseio e armazenamento dos recipientes (frascos de coleta) a fim de evitar a interferência nos resultados das análises.

As amostras devidamente identificadas foram armazenadas e transportadas em caixas térmicas abastecidas com gelo até a unidade de captação e desta até o laboratório, refrigeradas de 2 a $4{ }^{\circ} \mathrm{C}$. As amostras foram enviadas e analisadas em laboratório oficial da Rede Brasileira de Laboratórios de Controle de Qualidade do Leite (RBQL), no laboratório centralizado de análise de leite do Programa de Análise de Rebanhos Leiteiros do Paraná (PARLPR) da APCBRH, em Curitiba, PR. Os frascos plásticos com capacidade de $50 \mathrm{~mL}$ usados na coleta eram esterilizados e descartáveis. Coletou-se aproximadamente, $40 \mathrm{~mL}$ de amostra por frasco. Um frasco foi encaminhado para análise de CPP e outro para CCS e componentes, os quais continham os bacteriostáticos Azidiol e Bronopol, respectivamente.

Os valores de gordura (\%), proteína (\%), lactose (\%), Estrato Seco Total - EST (\%), CCS $\left(\mathrm{CS} \mathrm{ml}^{-1}\right)$ e CPP $\left(\mathrm{UFC} \mathrm{ml} \mathrm{m}^{-1}\right.$ ) foram avaliados. Com o valor do EST e da gordura substituiu-se na fórmula $\mathrm{ESD}=\mathrm{EST}-\mathrm{G}$ e pôde-se obter o valor do Estrato Seco Desengordurado - ESD (BEHMER 1987). As amostras foram submetidas em analisadores automatizados. Obteve-se a CPP e CCS pela técnica de Citometria de fluxo, conforme orientações da ISO 21187/IDF 196: 2004 e ISO 13366-2/IDF 1482:2006, respectivamente. Os demais componentes foram determinados por meio da leitura de absorção 
infravermelho, que captura o espectro completo de absorção da amostra de leite para o componente analisado.

O delineamento experimental foi inteiramente casualizado. Os dados coletados foram submetidos à análise de variância, sendo utilizado para comparação de médias o teste de Tukey a 5\% de probabilidade de erro. As análises foram realizadas por meio do programa estatístico Assistat (SILVA \& AZEVEDO 2009).

\section{RESULTADOS E DISCUSSÃO}

No presente estudo, entre as 40 unidades produtoras, $57,50 \%$ apresentaram área total da propriedade de até 20 ha, enquanto que 32,50\% dispõem de área entre 20 e 80 ha e $10 \%$ superior a 80 ha. Em propriedades com volume de produção de até 6.000 litros mensal, $86,36 \%$ delas dispõe área total de até 20 ha e 13,64\% superior a esta área. Porém, para o volume de produção de 6.001 a 12.000 litros e acima de 12.000 litros, $77,78 \%$ e $22,22 \%$ apresentaram área superior e inferior a 20 ha, respectivamente.

$\mathrm{O}$ plantel das unidades produtoras era composto por animais das raças Holandesa, Jersey, mestiço Holandês X Jersey e Girolando. Com relação aos volumes de produção e a raça dos animais, em propriedades com até 6.000 litros por mês, os plantéis eram compostos por $13,64,22,73,27,27$ e $36,36 \%$ pelas raças Holandesa e Jersey, Girolando, Jersey e mestiço Holandês X Jersey, respectivamente. No estrato de produção mensal de 6.001 a 12.000 litros, $33,33 \%$ do rebanho das propriedades eram da raça Jersey, bem como para a raça Holandesa e a cruza de Holandês X Jersey. Em todas as unidades produtoras com produção mensal superior a 12.000 litros, o rebanho era composto por animais da raça Holandesa.

$\mathrm{O}$ teor de gordura foi superior para as propriedades do estrato de produção até 6.000 litros em comparação com a produção mensal superior a 12.000 litros, porém semelhante ao estrato intermediário (6.001 a 12.000 litros), e este não diferiu das propriedades do estrato de maior produção (Tabela 2). Esta diferença pode estar vinculada ao fato de que os animais que compõe o plantel das propriedades que apresentam maior produção tendem a ser mais produtivos e, quanto maior a produtividade, menor a concentração de lipídios dissolvidos no leite, especialmente para os bovinos da raça Holandesa, predominante nas propriedades com maior produção.
Por meio do melhoramento genético é possível selecionar animais para maior produção em detrimento a composição sólida do leite, uma vez que muitos laticínios pagam o produtor com base principalmente no volume produzido, a fim de reduzir custos de logística na captação, deixando de avaliar os impactos negativos da menor composição dos sólidos no rendimento industrial. CHAUHAN \& HAYES (1991) encontraram valores de herdabilidade para produção e porcentagem de gordura de 0,31 e 0,65 , respectivamente, demonstrando que a gordura do leite é influenciada consideravelmente pela genética. A quantidade disponível de proteína e de gordura do leite é economicamente importante porque o rendimento dos derivados, especialmente dos queijos é dependente destes componentes (VAN SLYKE 1984).

Estabelecimentos menos produtivos em termos quantitativos, geralmente usam uma maior proporção de volumoso em relação ao concentrado na alimentação dos animais. Conforme SUTTON (1989), a participação de forragens na dieta dos animais é o fator mais impactante na concentração de gordura no leite. Animais cruzados, Holandês X Jersey e Girolando, predominantes nos rebanhos dos estabelecimentos com menor produção produzem leite com mais teor de gordura. Este conceito condiz com trabalho realizado por VANCE et al. (2012), onde a produção de gordura foi superior em animais meiosangue Jersey e Holandês do que em Holandês puro.

Para a lactose, observou-se diferença significativa entre os estratos deprodução intermediário e menor $(4,46$ e 4,38\%, respectivamente), porém, não diferiram das propriedades do maior estrato de produção $(4,43 \%)$. O menor valor de lactose encontrado nas propriedades do menor estrato de produção pode estar relacionado com a contaminação bacteriana mais elevada em relação ao estrato intermediário. A lactose é utilizada no processo de fermentação bacteriana, produzindo ácido lático, o que compromete a integridade da composição do leite e de acordo com o grau de acidez, torna-o impróprio para a produção de determinados derivados. O resultado obtido em trabalho realizado por BUENO et al. (2008) corrobora com o resultado encontrado para esta variável, onde analisaram 16.491 amostras de leite provenientes do Estado de Goiás e conforme ocorria elevação da CPP, diminuía o teor de lactose.

Obteve-se diferença significativa para a CPP nos estratos de produção avaliados 
Tabela 2 - Influência do nível e sistema de produção, tipo de ordenha e resfriamento para os valores de gordura $(\%)$, proteína (\%), lactose (\%), extrato seco total (\%), contagem de células somáticas (CS $\left.\mathrm{mL}^{-1}\right)$ e contagem padrão em placas (UFC $\mathrm{mL}^{-1}$ ) obtidos do leite em propriedades na região Sudoeste do Paraná no período de julho de 2012 a junho de 2014.

Table 2 -Influence level and production system, type of milking and cooling of the fat values (\%), Protein (\%), Lactose (\%), total solids (\%), somatic cell count $\left(C S m L^{-1}\right)$ and standard plate count $\left(\mathrm{CFU} \mathrm{mL}^{-1}\right.$ ) obtained from milk in properties in southwestern Paraná region from July 2012 to June 2014.

\begin{tabular}{|c|c|c|c|c|c|c|c|}
\hline $\begin{array}{l}\text { Variáveis } \\
\text { independentes }\end{array}$ & $\begin{array}{c}\text { Gordura } \\
(\%)\end{array}$ & $\begin{array}{c}\text { Proteína } \\
(\%)\end{array}$ & $\begin{array}{c}\text { Lactose } \\
(\%)\end{array}$ & $\begin{array}{l}\text { EST } \\
(\%)\end{array}$ & $\begin{array}{c}\mathrm{CCS} \\
\left(\mathrm{x} 10^{3}\right)\end{array}$ & $\begin{array}{c}\text { CPP } \\
\left(\mathrm{x} 10^{3}\right)\end{array}$ & $\mathrm{n}$ \\
\hline \multicolumn{8}{|c|}{ Níveis de produção mensal (litros) } \\
\hline Até 6.000 & $3,93 \mathrm{a}$ & $3,18 \mathrm{~ns}$ & $4,38 \mathrm{~b}$ & $12,45 \mathrm{~ns}$ & $673 \mathrm{~ns}$ & $2.250 \mathrm{a}$ & 22 \\
\hline $6.001-12.000$ & $3,80 \mathrm{ab}$ & 3,21 & $4,46 \mathrm{a}$ & 12,42 & 627 & $1.225 \mathrm{ab}$ & 9 \\
\hline Acima de 12.000 & $3,63 \mathrm{~b}$ & 3,15 & 4,43ab & 12,14 & 707 & $579 \mathrm{~b}$ & 9 \\
\hline Média & 3,79 & 3,18 & 4,42 & 12,34 & 669 & 1.351 & \\
\hline $\mathrm{CV}(\%)$ & 6,20 & 3,46 & 1,64 & 2,85 & 40,51 & 69,68 & \\
\hline \multicolumn{8}{|c|}{ Sistema de produção } \\
\hline Confinado & $3,60 \mathrm{~ns}$ & $3,16 \mathrm{~ns}$ & $4,46 \mathrm{~ns}$ & $12,17 \mathrm{~ns}$ & $605 \mathrm{~ns}$ & $290 \mathrm{~b}$ & 3 \\
\hline Misto & 3,85 & 3,18 & 4,40 & 12,39 & 676 & $1.639 \mathrm{a}$ & 37 \\
\hline Média & 3,73 & 3,17 & 4,43 & 12,28 & 640 & 964 & \\
\hline CV $(\%)$ & 6,71 & 3,47 & 1,75 & 2,96 & 40,08 & 71,92 & \\
\hline \multicolumn{8}{|c|}{ Sistema de ordenha } \\
\hline Balde ao pé & $3,89 \mathrm{~ns}$ & $3,17 \mathrm{~ns}$ & $4,39 \mathrm{~ns}$ & $12,43 \mathrm{~ns}$ & $655 \mathrm{~ns}$ & $2.114 \mathrm{a}$ & 23 \\
\hline Canalizado & 3,72 & 3,18 & 4,43 & 12,27 & 708 & $546 \mathrm{~b}$ & 14 \\
\hline Manual & 3,90 & 3,18 & 4,41 & 12,45 & 612 & $3.150 \mathrm{a}$ & 3 \\
\hline Média & 3,84 & 3,18 & 4,41 & 12,38 & 658 & 1.937 & \\
\hline CV (\%) & 6,64 & 3,52 & 1,75 & 2,97 & 40,46 & 62,96 & \\
\hline \multicolumn{8}{|c|}{ Sistema de resfriamento } \\
\hline Expansão & $3,80 \mathrm{~ns}$ & $3,17 \mathrm{~ns}$ & $4,41 \mathrm{~ns}$ & $12,33 \mathrm{~ns}$ & $683 \mathrm{~ns}$ & $1.303 \mathrm{~b}$ & 31 \\
\hline Imersão & 3,95 & 3,18 & 4,42 & 12,52 & 628 & $2.310 \mathrm{a}$ & 9 \\
\hline Média & 3,88 & 3,18 & 4,42 & 12,43 & 655 & 1.806 & \\
\hline CV $(\%)$ & 6,74 & 3,47 & 1,79 & 2,93 & 40,03 & 70,31 & \\
\hline
\end{tabular}

Resultados seguidos de letras distintas na coluna diferem estatisticamente entre si pelo teste de Tukey $(\mathrm{p}<0,05)$ para cada variável estudada. $\mathrm{ns}=$ não significativo.

(Tabela 2). Os resultados mostram que a contaminação bacterina apresentou-se superior no menor estrato de produção em relação ao maior, no entanto, não diferiram estatisticamente do estrato intermediário. A contaminação microbiana superior aos limites estabelecidos pela legislação (IN 62) é indicativa de deficiência na limpeza e higienização, principalmente dos tetos, dos equipamentos de ordenha e do sistema de resfriamento. Estabelecimentos com menor produção obtêm consequentemente uma receita menor. A maioria destas propriedades conta com o dinheiro da venda do leite primeiramente para o custeio de despesas básicas da família, como alimento, energia, roupa, entre outros e que em muitas vezes, ainda não é suficiente. Desta forma, os investimentos na atividade leiteira ficam em segundo plano e os procedimentos de rotina são realizados da forma mais econômica possível. Em função disso, algumas práticas de manejo que poderiam melhorar a qualidade microbiológica deixam de ser realizadas, como a desinfecção dos tetos e o uso de papel toalha.

Não se verificou diferença significativa para proteína, EST e CCS, com valores médios de 3,18\%, $12,34 \%$ e $669 \times 10^{3} \mathrm{CS} \mathrm{mL}^{-1}$, entre propriedades com nível produtivo distintos, respectivamente. As células somáticas são constituídas por células de defesa e epiteliais, sendo desta forma um parâmetro para monitorar a qualidade do leite quanto à ocorrência de mastite. As células de defesa migram para o úbere quando este sofre alguma agressão, como por exemplo, nos casos de infecções (VIANA et al. 2010). Os resultados obtidos para CCS nos diferentes 
estratos de produção foram semelhantes, e acima do estabelecido na legislação (BRASIL 2011). A diferença observada no teor de gordura do menor para o maior estrato de produção não influenciou para alteração significativa dos sólidos totais nos estratos de produção. O valor médio encontrado foi $12,34 \%$, semelhante aos obtidos por MACHADO et al. (2000), analisando 920 amostras de leite de tanques no Estado de São Paulo e no Sul de Minas Gerais e obtiveram média de $12,37 \%$ e desvio-padrão de $0,68 \%$.

Os estudos para o sistema de produção foram realizados mediante a classificação das propriedades em dois grupos, confinado e misto. Não se obteve diferença estatística para gordura, proteína, lactose, EST e CCS (Tabela 2). Resultados diferentes foram encontrados por WHITE et al. (2002), avaliando o sistema confinado com dieta total e sistemas a pasto com suplementação, observaram menor produção de leite e maior porcentagem de proteína $(3,5 \%)$ no sistema a pasto do que o sistema de confinamento $(3,4 \%)$. Os animais que compõe o rebanho de sistema de produção confinado são predominantemente da raça Holandesa, os quais apresentam maior produtividade por animal e recebem uma dieta balanceada com maior participação de concentrado devido seu maior potencial produtivo em relação aos animais da raça Jersey ou suas cruzas presentes no sistema misto, este fator pode refletir na composição de sólidos totais. A CCS em ambos os sistemas não diferiram, no entanto, permaneceram acima do limite máximo estabelecido na IN 62 (BRASIL 2011).

A alta CCS está relacionada à diminuição da produção de leite. Conforme SANTOS \& FONSECA (2002), esta redução na produção ocorre em razão dos danos físicos nas células epiteliais secretoras da glândula mamária e nas alterações da permeabilidade vascular do alvéolo secretor. A CPP apresentou diferença significativa (Tabela 2), sendo inferior no sistema confinado em relação ao misto. A tecnologia e a aplicabilidade de práticas de manejo tecnicamente recomendadas são os alicerces na obtenção dos objetivos esperados, nesse caso, a baixa contaminação microbiana, conforme estabelecido na legislação para o período (BRASIL 2011). No sistema misto, acreditase que algumas práticas inadequadas de manejo de ordenha e de higienização podem ter contribuído para a significativa contaminação microbiana do leite. Dentre as principais práticas adequadas de manejo pode-se destacar o uso de pré-dipping, secagem dos tetos com papel toalha descartável, uso de pós- dipping após a ordenha, limpeza com detergente alcalino ou ácido e temperatura adequada (SANTOS 2007). É importante destacar que a qualidade do leite está diretamente relacionada com o tipo de manejo adotado na produção, independentemente do nível tecnológico da propriedade e a aplicação das boas práticas é essencial para a obtenção de matériasprimas de qualidade (GUIDO et al. 2010).

Entre os sistemas de ordenha, não foi verificada diferença na composição centesimal para gordura, proteína, lactose, EST e CCS (Tabela 2). Não se obteve diferença para CPP entre os sistemas manual e mecanizado balde ao pé, porém ambos diferiram do sistema canalizado, o qual apresentou menor valor. TAFFAREL et al. (2013) também não encontraram diferença entre a CPP do leite ordenhado no sistema balde ao pé e manual.

Com o investimento no sistema de ordenha mecanizado balde ao pé, além de obter mais conforto, o produtor já começa a ter uma visão rentável da atividade e começa a se preocupar mais com as possibilidades de aumentar o seu retorno financeiro e, a preocupação de oferecer um leite com qualidade de acordo com a demanda, passa a se tornar interessante, principalmente quando as unidades industriais bonificam para este quesito. Porém, os resultados encontrados não condizem com a legislação (BRASIL 2011) em vigor para CPP. Neste sistema, as superfícies de contato são inúmeras e os descuidos nas etapas da ordenha e na higienização são cruciais para o comprometimento da integridade dos componentes do leite. A manutenção dos componentes da unidade da ordenha de acordo com a necessidade ou conforme recomendações do fabricante influenciam diretamente na qualidade microbiológica do leite, pois insufladores, registros danificados, mangueiras com depósito de minerais são fontes diretas de contaminação (ZAFALON et al. 2008). Estes fatores, aliados com a pressão de vácuo adequada são garantias de uma ordenha ininterrupta e completa, além de prevenir focos de infecção e inflamação intramamária.

O sistema manual de ordenha, no presente estudo, também não apresentou valores dentro dos padrões estabelecidos pela IN 62. O sistema é vulnerável a diversos fatores que podem ter propiciado a elevada carga microbiana, como o uso de diversos utensílios até o armazenamento para resfriamento e maior exposição do leite ao ambiente com possíveis contaminantes. No ato da ordenha, no movimento de 
pressão para extrair o leite, há possibilidade de cair sujidades, pelos dos animais e poeira no recipiente de depósito. Já o sistema mecanizado canalizado apresentou valores dentro do padrão desejado na normativa e inferior aos outros dois sistemas. CAVALCANTI et al. (2010) relatam que amostras obtidas por ordenhadeira canalizada apresentaram a menor CPP, sugerindo melhor qualidade do leite, possivelmente pela redução das principais fontes de contaminação do leite cru. A execução de práticas de manejo tecnicamente recomendadas no preparo dos animais para a ordenha, como a utilização de água na limpeza nos tetos quando necessário, o uso de papel toalha, o uso do pré-dipping aliadas com a manutenção das unidades de ordenha a fim de eliminar os focos de contaminação e condução do leite até o sistema de resfriamento por circuito fechado, sem contato com o ambiente externo, são fatores primordiais e que justificam o resultado obtido.

Para os métodos de resfriamento nas propriedades estudadas, expansão e imersão (Tabela 2), foi verificada diferença significativa apenas para os valores de CPP $\left(1.303 \times 10^{3}\right.$ e $2.310 \times 10^{3}$, respectivamente). TAFFAREL et al. (2013) encontraram diferença $(p<0,05)$ na CPP do leite coletado em diferentes refrigeradores. Estes resultados condizem com os encontrados por CORDIOLI et al. (2009), que verificaram valores mais baixos de CPP do leite armazenado em sistema de resfriamento a granel do que no leite estocado em sistema de imersão.

Quanto mais rápido reduzir a temperatura do leite (resfriamento), menor será a composição de microorganismos, pois restringe a proliferação dos mesmos. O resultado do crescimento microbiano, principalmente das bactérias, é a alteração das características de qualidade do leite, como fermentação da lactose e degradação da proteína e gordura. O resfriamento por expansão visa reduzir temperatura do leite a $4{ }^{\circ} \mathrm{C}$ em até três horas após a ordenha, possibilitando o resfriamento mais uniforme do leite, através da expansão de gás em câmeras internas e com agitação mecânica (HORST 2006).

Embora o resultado encontrado para a refrigeração por expansão ser inferior ao de imersão para CPP não atende aos requisitos da IN 62, isso porque o resfriamento faz parte do processo, ou seja, é apenas uma etapa, em que, se realizado corretamente, mantém a integridade do leite depositado. Observouse diferença estatística para o teor de gordura e para $\mathrm{CPP}$ em relação à mão de obra utilizada na atividade leiteira (Tabela 3). Em sistemas de produção intensivos ou tecnificados, a produtividade dos animais tende a ser mais expressiva em relação aos sistemas mais rudimentares. Em estabelecimentos com mão de obra familiar percebeu-se maior presença de animais mestiços e Jersey, além de predominar o sistema misto de produção, com maior participação de pastagens na dieta dos animais. Isso contribui para o esclarecimento da diferença obtida nos valores de gordura, sendo superior em propriedades com mão de obra familiar perante a contratada.

A contaminação microbiana no leite em propriedades com mão de obra familiar foi superior à apresentada pela mão de obra contratada. As atividades que envolvem o trabalho assalariado são passíveis de complementar a remuneração do empregado por meio de comissão. Sendo assim, na atividade leiteira, quando o pagamento da matéria-prima vai além da produção e os requisitos qualitativos influenciam na receita final, o empregador pode estabelecer uma bonificação por cumprimento de metas atingidas neste quesito. Essa atitude pode concentrar esforços dos envolvidos no processo a conquistar os melhores resultados possíveis e consequentemente, a remuneração. Esta hipótese provavelmente esta relacionada com a menor quantidade de CPP obtida com a mão de obra contratada, porém, acima da legislação. Não foram observadas diferenças para proteína, lactose, EST e CCS para os diferentes tipos de mão de obra empregada.

Não se verificou diferença significativa entre as propriedades que recebem assistência técnica e as que não são assistidas para todas as variáveis estudadas (Tabela 3). Atualmente, informações técnicas são obtidas por diversos meios, seja impresso, digital ou pela troca de experiências. A região Sudoeste foi colonizada por diferentes etnias e culturas, nesse sentido, é comum observar a ideologia de que os procedimentos realizados pelos ascendentes são os corretos ainda prevalecem, ou seja, a resistência pela assimilação de novos conhecimentos e tecnologias ainda é evidente. Isso está bastante relacionado, a idade avançada dos que ainda labutam na zona rural e em especial na atividade leiteira. Percebese que quando os envolvidos na atividade são mais jovens e detêm um grau de escolaridade maior, os conceitos científicos e tecnológicos são aplicados mais incisivamente.

Outro fator a considerar é a qualidade e o objetivo da assistência técnica. $\mathrm{O}$ poder aquisitivo 
Tabela 3 - Influência da mão de obra, assistência técnica e frequência da assistência técnica para os valores de gordura (\%), proteína (\%), lactose $(\%)$, extrato seco total $(\%)$, contagem de células somáticas $\left(\mathrm{CS} \mathrm{mL} \mathrm{m}^{-1}\right)$ e contagem padrão em placas (UFC $\mathrm{mL}^{-1}$ ) obtidos do leite em propriedades na região Sudoeste do Paraná no período de julho de 2012 a junho de 2014.

Table 3 - Influence of hand labor, technical assistance and frequency of technical assistance for fat values (\%), protein (\%), lactose (\%), total solids (\%), somatic cell count (CS $\left.\mathrm{mL}^{-1}\right)$ and standard plate count $\left(C F U \mathrm{~mL}^{-1}\right)$ obtained from milk in properties in southwestern Paraná region from July 2012 to June 2014.

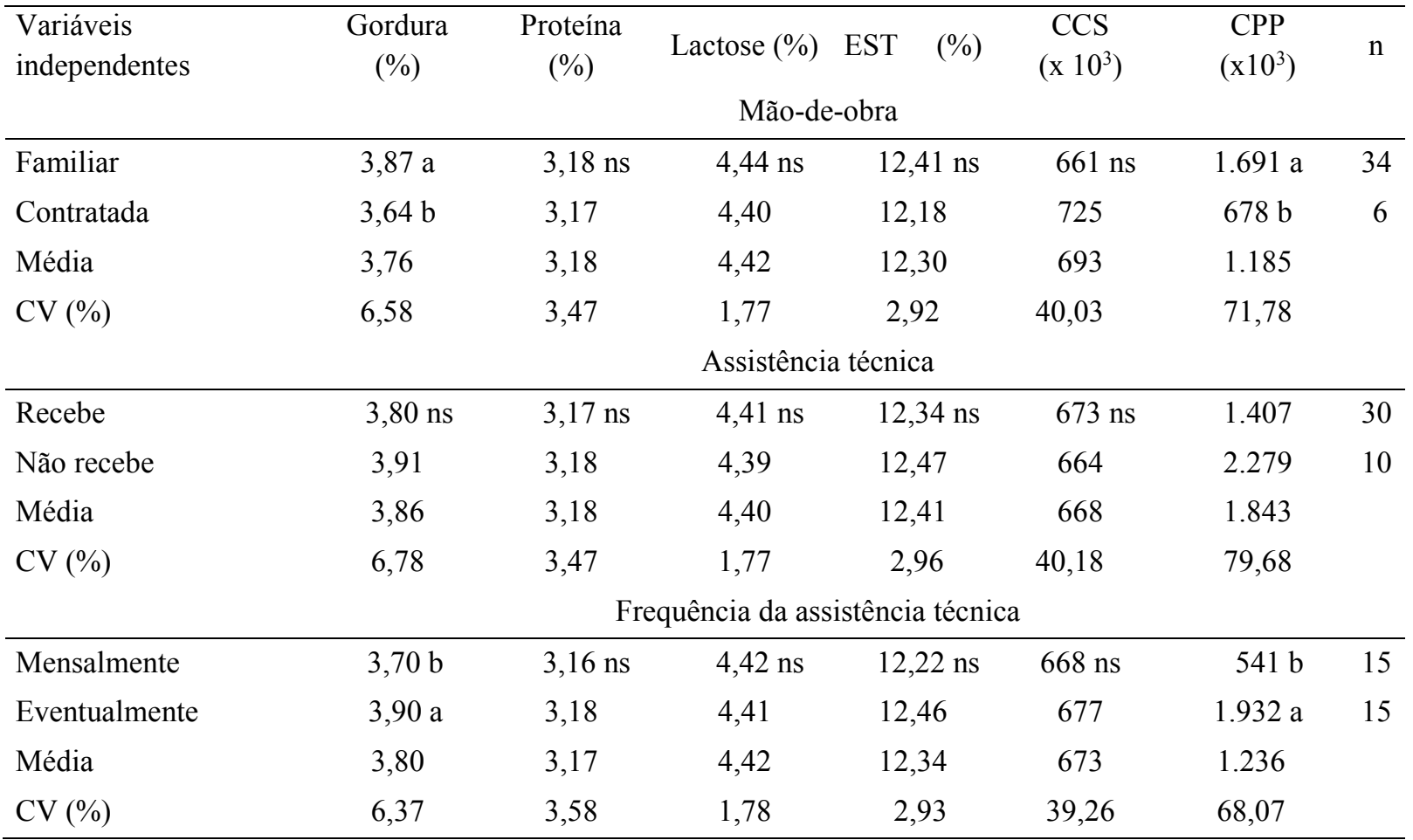

Resultados seguidos de letras distintas na coluna diferem estatisticamente entre si pelo teste de Tukey $(\mathrm{p}<0,05)$ para cada variável estudada. ns = não significativo.

e de investimento tem prosperado nos últimos anos na cadeia do agronegócio e nela a pecuária leiteira está inserida. Com base nisso, o comércio varejista tem explorado a venda de insumos agropecuários e juntamente a prática de assistência técnica. Muitas vezes, os produtos são ineficientes ou utilizados de forma incorreta, não apresentando os resultados esperados e consequentemente corroem a receita do produtor.

Em relação à frequência da assistência técnica, observa-se influencia apenas para gordura e CPP (Tabela 3). Sendo que o menor valor para CPP foi observado nos estabelecimentos que dispõe de assistência técnica mensal. Os procedimentos de manejo para dispor de leite com baixa contaminação microbiana são básicos e facilitados quando as unidades produtivas são estruturadas tecnicamente. Quando há uma assistência técnica frequente e atuante, que oferece respaldo quanto aos resultados obtidos decorrentes do procedimento aplicado, a prática não é interrompida. Porém, quando não dispõem de dados conclusivos considera-se uma ação paliativa e passa a ser ignorada. Propriedades assistidas mensalmente apresentaram menor valor de CPP, dentro dos limites da legislação (BRASIL 2011). As demais variáveis não diferiram estatisticamente.

Os estabelecimentos que utilizaram água fria e detergente na higienização do resfriador apresentaram diferença significativa para os valores de gordura, EST e CPP e não diferiram para os valores de proteína, lactose e CCS, comparado com as que usavam água quente e detergente (Tabela 4). As propriedades que utilizaram o primeiro procedimento apresentam menor produção mensal e animais pouco produtivos e provenientes de cruzas, as quais produzem leite com mais sólidos gordurosos, sendo a gordura o componente que mais oscila em resposta a genética e a alimentação. Este fato também contribuiu 
Tabela 4 - Influência do método de higienização do resfriador, ordenhadeira, tetos e desinfecção dos tetos para os valores de gordura (\%), proteína (\%), lactose (\%), extrato seco total $(\%)$, contagem de células somáticas $\left(\mathrm{CS} \mathrm{mL}^{-1}\right)$ e contagem padrão em placas $\left(\mathrm{UFC} \mathrm{mL}^{-1}\right)$ obtidos do leite em propriedades na região Sudoeste do Paraná no período de julho de 2012 a junho de 2014.

Table 4 - Influence of cooler cleaning method, milking teat disinfection for fat values (\%), protein (\%), lactose $(\%)$, total solids (\%), somatic cell count $\left(C S \mathrm{~mL}^{-1}\right)$ and standard plate count $\left(C F U \mathrm{~mL}^{-1}\right)$ obtained from milk in properties in southwestern Paraná region from July 2012 to June 2014.

\begin{tabular}{|c|c|c|c|c|c|c|c|}
\hline $\begin{array}{l}\text { Variáveis } \\
\text { independentes }\end{array}$ & $\begin{array}{c}\text { Gordura } \\
(\%)\end{array}$ & $\begin{array}{c}\text { Proteína } \\
(\%)\end{array}$ & Lactose (\%) & $\begin{array}{l}\text { EST } \\
(\%)\end{array}$ & $\begin{array}{c}\mathrm{CCS} \\
\left(\mathrm{x} 10^{3}\right)\end{array}$ & $\begin{array}{c}\text { CPP } \\
\left(\times 10^{3}\right)\end{array}$ & $\mathrm{n}$ \\
\hline \multicolumn{8}{|c|}{ Higienização do resfriador } \\
\hline Água fria e detergente & $3,92 \mathrm{a}$ & $3,18 \mathrm{~ns}$ & $4,41 \mathrm{~ns}$ & $12,47 \mathrm{a}$ & $597 \mathrm{~ns}$ & $2.028 \mathrm{a}$ & 23 \\
\hline $\begin{array}{l}\text { Água quente e } \\
\text { detergente }\end{array}$ & $3,67 \mathrm{~b}$ & 3,18 & 4,43 & $12,22 \mathrm{~b}$ & 695 & $509 \mathrm{~b}$ & 17 \\
\hline Média & 3,80 & 3,18 & 4,42 & 12,35 & 646 & 1.268 & \\
\hline CV (\%) & 6,37 & 3,60 & 1,86 & 2,81 & 41,65 & 58,22 & \\
\hline \multicolumn{8}{|c|}{ Higienização da ordenhadeira } \\
\hline Água fria e detergente & $3,76 \mathrm{~ns}$ & $3,18 \mathrm{~ns}$ & $4,43 \mathrm{~ns}$ & $12,32 \mathrm{~ns}$ & $673 \mathrm{~ns}$ & $3.376 \mathrm{a}$ & 4 \\
\hline $\begin{array}{l}\text { Água quente e } \\
\text { detergente }\end{array}$ & 3,82 & 3,19 & 4,41 & 12,37 & 653 & $1.275 \mathrm{~b}$ & 36 \\
\hline Média & 3,79 & 3,19 & 4,42 & 12,35 & 663 & 2.326 & \\
\hline CV (\%) & 7,14 & 3,61 & 1,85 & 2,98 & 42,61 & 77,53 & \\
\hline \multicolumn{8}{|c|}{ Higienização dos tetos } \\
\hline Água & $3,92 \mathrm{~ns}$ & $3,20 \mathrm{~ns}$ & $4,40 \mathrm{~ns}$ & $12,49 \mathrm{~ns}$ & $590 \mathrm{~ns}$ & $2.117 \mathrm{a}$ & 10 \\
\hline Água e papel toalha & 3,71 & 3,16 & 4,42 & 12,25 & 729 & $601 \mathrm{~b}$ & 17 \\
\hline Água e pano & 3,92 & 3,17 & 4,40 & 12,44 & 656 & $2.641 \mathrm{a}$ & 13 \\
\hline Média & 3,85 & 3,18 & 4,41 & 12,39 & 658 & 1.786 & \\
\hline CV (\%) & 6,44 & 3,49 & 1,80 & 2,90 & 39,79 & 58,94 & \\
\hline \multicolumn{8}{|c|}{ Desinfecção dos tetos } \\
\hline Pré e pós-dipping & $3,71 \mathrm{~ns}$ & $3,19 \mathrm{~ns}$ & $4,44 \mathrm{~ns}$ & $12,28 \mathrm{~ns}$ & $654 \mathrm{~ns}$ & $387 \mathrm{~b}$ & 12 \\
\hline Pós-dipping & 3,85 & 3,18 & 4,39 & 12,37 & 682 & $2.117 \mathrm{a}$ & 17 \\
\hline Não faz & 3,95 & 3,16 & 4,40 & 12,48 & 670 & $2.184 \mathrm{a}$ & 11 \\
\hline Média & 3,84 & 3,18 & 4,41 & 12,38 & 669 & 1.563 & \\
\hline CV (\%) & 6,58 & 3,49 & 1,75 & 2,98 & 40,68 & 65,95 & \\
\hline
\end{tabular}

Resultados seguidos de letras distintas na coluna diferem estatisticamente entre si pelo teste de Tukey $(\mathrm{p}<0,05)$ para cada variável estudada. ns = não significativo.

diretamente para o maior valor obtido de sólidos totais. O EST está diretamente relacionado com o rendimento dos derivados lácteos. A manutenção da integridade dos componentes do leite proporciona um melhor aproveitamento no processamento industrial e consequentemente uma melhor remuneração para os agentes envolvidos na cadeia produtiva.

$\mathrm{O}$ resultado de CPP com uso de água quente e detergente na higienização do resfriador diferiu estatisticamente (Tabela 4), sendo inferior ao resultado obtido no uso de água fria e detergente, destacando-se que a CPP nas propriedades que fazem a higienização do resfriador com água quente e detergente atende o requisito da IN 62. A higienização preconiza remover os resíduos e controlar os microrganismos, e neste processo a água aquecida favorece a retirada da gordura e melhora a ação do detergente alcalino, assim como o uso do detergente ácido periodicamente visa eliminar os resíduos minerais. A água obtida de nascentes sem proteção, caixas d'água ao ar livre podem apresentar 
uma elevada carga bacteriana, causando o efeito de contaminação cruzada. Equipamentos inadequados, como vassoura de palha são fontes contaminantes e que devem ser evitados, bem como utensílios que danificam a parede interna exposta ao leite.

$\mathrm{Na}$ higienização da ordenhadeira, verificouse diferença apenas para a CPP, com valor inferior quando utilizado água quente e detergente (Tabela 4). O enxágue retira os resíduos solúveis em água fria, porém não é eficiente na limpeza, causando a formação de biofilmes, devido à solidificação da gordura, local estratégico para abrigar os microrganismos. Equipamento de ordenha canalizado dispõe de aquecedor automático, o que facilita o processo de higienização. ARCURI et al. (2006) encontraram CPP $<105 \mathrm{UFC} \mathrm{mL}^{-1}$ em rebanhos cujo procedimento de limpeza de equipamentos seguia a recomendação de uso de detergente alcalino e ácido. Os dois métodos avaliados para higienização da ordenha estão acima dos limites estabelecidos pela Legislação Brasileira para a CPP.

$\mathrm{Na}$ higienização dos tetos, não se verificou diferença estatística para gordura, proteína, lactose, EST e CCS nos três métodos avaliados (Tabela 4). A utilização de água e papel toalha apresentou resultado significativamente menor para CPP que o uso de somente água ou água e pano. Na prática de lavar os tetos e não proceder a secagem, a água servirá de carreador de microrganismos para o leite no ato da ordenha, além da possibilidade de molhar a base da úbere, e durante a ordenha a água contaminada pode escorrer para o interior das teteiras, quando mecanizado ou cair no leite na ordenha manual. O método de lavar e secar com o pano, e usá-lo de uma vaca para outra sem uso de sanitizante é uma forma de disseminar a contaminação e dispor os animais a uma possível ocorrência de mastite. O uso do papel toalha não deveria ser considerado um custo adicional, mas um investimento que propicia retorno qualitativo, com uma menor carga microbiana no leite.

Quanto à desinfecção dos tetos verificou-se diferença apenas para CPP (Tabela 4). A realização do pré e pós-dipping diferenciou dos estabelecimentos que não fazem a desinfecção ou apenas o pós-dipping. $\mathrm{O}$ menor valor obtido evidencia a capacidade bactericida do pré-dipping na composição bacteriana do leite. A não realização da desinfecção é caracterizada por uma carga elevada de microrganismos no leite, o que permite definir que a colonização de contaminantes nos tetos é elevada.
O pós-dipping não apresenta efeito sobre a carga microbiana do leite, uma vez que atua mais na prevenção de infecção intramamária, principalmente nas duas horas após a ordenha. Esperava-se que propriedades que não fazem o uso de pós-dipping apresentassem maior CCS, porém essa hipótese não foi confirmada. As falhas no pré e pós-dipping estão associadas ao uso inadequado de desinfetantes (CAVALCANTI et al. 2010), e possivelmente, associado ao uso de produtos de qualidade questionável e armazenamento inadequado. A CCS está diretamente relacionada com a longevidade produtiva e o descarte de animais. Por isso, deve-se dar atenção especial as práticas de manejo que visem manter a sanidade do úbere, pois a reposição de uma fêmea no plantel seja pela produção de novilhas na própria propriedade ou por aquisição de terceiros, é subsidiada pela própria atividade.

A influência de diferentes estruturas de ambiente de ordenha foi observada na Tabela 5 . A CPP diferiu para os três tipos de estrutura, sendo superior na contenção de madeira com piso de chão batido. Nesses ambientes, os agentes contaminantes são aumentados, como poeira e resíduos de forragens. Conforme observado durante os estudos, quase na totalidade, a ordenha é realizada manualmente, onde o leite fica mais exposto ao ambiente e passível de contaminação. Ainda a forma de refrigeração, predominante por imersão, que demora mais para atingir a temperatura ideal de armazenamento e consequentemente a proliferação dos microrganismos é aumentada.

SANTOS \& FONSECA (2007) salientam que os microrganismos ambientais são oportunistas e a transmissão pode ocorrer no período de ordenhas ou entre elas. $\mathrm{O}$ ambiente com estrutura de ferro e piso de alvenaria apresentou CPP menor que os demais ambientes de ordenha. Estas propriedades mais estruturadas tecnicamente realizam procedimentos de manejo de ordenha, higienização dos equipamentos de ordenha e de resfriamento adequado. $\mathrm{O}$ ambiente com contenção de madeira com piso de alvenaria teve contaminação bacteriana superior à contenção de ferro com piso de alvenaria e menor que contenção de madeira e piso de chão batido. Produtores que disponibilizam de piso de alvenaria e contenção de ferro tem mais comprometimento e zelo na atividade através da adoção de medidas adequadas de manejo. Nos demais sistemas, é comum encontrar produtores não comprometidos com a causa, que deixam a desejar 
Tabela 5 - Influência da estrutura do ambiente de ordenha para os valores de gordura (\%), proteína (\%), lactose $(\%)$, extrato seco total (\%), contagem de células somáticas $\left(\mathrm{CS} \mathrm{mL}^{-1}\right)$ e contagem padrão em placas (UFC mL $\mathrm{mL}^{-1}$ ) obtidos do leite em propriedades na região Sudoeste do Paraná no período de julho de 2012 a junho de 2014.

Table 5 - Influence of the structure of the milking environment for fat values (\%) protein (\%), lactose (\%), total solids (\%), somatic cell count $\left(C S \mathrm{~mL}^{-1}\right)$ and standard plate count $\left(C F U \mathrm{~mL}^{-1}\right)$ obtained from milk in properties in southwestern Paraná region from July 2012 to June 2014.

\begin{tabular}{lccccccc}
\hline $\begin{array}{l}\text { Variáveis } \\
\text { independentes }\end{array}$ & Gordura (\%) & Proteína (\%) & $\begin{array}{c}\text { Lactose } \\
(\%)\end{array}$ & $\begin{array}{c}\text { EST } \\
(\%)\end{array}$ & $\begin{array}{c}\text { CCS } \\
(\mathrm{x} \mathrm{103})\end{array}$ & $\begin{array}{l}\text { CPP } \\
\left(\mathrm{x} 10^{3}\right)\end{array}$ & $\mathrm{n}$ \\
\hline $\begin{array}{l}\text { Contenção de ferro e } \\
\text { piso de alvenaria }\end{array}$ & $3,64 \mathrm{~b}$ & $3,14 \mathrm{~ns}$ & $4,43 \mathrm{~ns}$ & $12,15 \mathrm{~ns}$ & $741 \mathrm{~ns}$ & $484 \mathrm{c}$ & 9 \\
$\begin{array}{l}\text { Contenção de madeira e } \\
\text { piso de alvenaria }\end{array}$ & $3,87 \mathrm{ab}$ & 3,18 & 4,41 & 12,42 & 636 & $1.641 \mathrm{~b}$ & 26 \\
$\begin{array}{l}\text { Contenção de madeira e } \\
\text { piso de chão batido }\end{array}$ & $4,00 \mathrm{a}$ & 3,18 & 4,39 & 12,52 & 723 & $2.895 \mathrm{a}$ & 5 \\
$\begin{array}{l}\text { Média } \\
\text { CV (\%) }\end{array}$ & 3,84 & 3,17 & 4,41 & 12,36 & 700 & 1.673 & \\
\hline
\end{tabular}

Resultados seguidos de letras distintas na coluna diferem estatisticamente entre si pelo teste de Tukey $(\mathrm{p}<0,05)$ para cada variável estudada. ns = não significativo.

quanto às medidas de limpeza, higiene e resfriamento. Não se observou diferença estatística para proteína, lactose, EST e CCS.

Percebe-se que uma grande parcela de propriedades não atendem os requisitos estabelecidos na legislação para CPP e CCS. Embora haja uma legislação vigente, o livre mercado e a falta de uma fiscalização eficiente em relação às exigências da qualidade do leite colocam os estabelecimentos produtivos em situação cômoda, pois sempre haverá um laticínio disposto a absorver a produção, indiferente ao histórico de qualidade obtido em laboratório oficial.

\section{CONCLUSÃO}

Aspectos nutricionais que promovem o aumento da produção, como identificado nos sistemas de maior produção de leite resultam em menor percentual de gordura do leite.

Instalações que apresentam a ordenha canalizada e resfriamento por expansão proporcionam melhores resultados para CPP.

Práticas como o uso de pré e pós-dipping, higienização do resfriador e ordenhadeira com água quente e detergente reduz significativamente a CPP.

\section{REFERÊNCIAS}

ALEIXO SS et al. 2007. Técnicas de análise multivariada na determinação de grupos homogêneos de produtores de leite. Revista Brasileira de Zootecnia 36: 2168-2175.

ARCURI EF et al. 2006. Qualidade microbiológica do leite refrigerado nas fazendas. Arquivo Brasileiro de Medicina Veterinária e Zootecnia 58: 440-446.

BELOTI V et al. 2011. Qualidade microbiológica e físicoquímica do leite cru refrigerado produzido no município de Sapopema/PR. Revista Científica Eletrônica de Medicina Veterinária 16: 1-9.

BRASIL. 2002. Ministério da Agricultura, Pecuária e Abastecimento. Regulamento técnico de Identidade e Qualidade de Leite. IN: BRASIL. Ministério da Agricultura, Pecuária e Abastecimento. Instrução Normativa $\mathrm{N}^{\circ} 51$, de 18 de setembro de 2002. Diário Oficial da União, 20 set. 2002. Seção 1.

BRASIL. 2006. Ministério da Agricultura, Pecuária e Abastecimento. Métodos analíticos oficiais físico-químicos para controle de leite e produtos lácteos. IN: BRASIL. Ministério da Agricultura, Pecuária e Abastecimento. Instrução Normativa 68, de 12 de dezembro de 2006. Diário Oficial da União, 14 dez. 2006. Seção 1.

BRASIL. 2011. Ministério da Agricultura, Pecuária e Abastecimento. Regulamento técnico de Identidade e Qualidade de Leite. IN: BRASIL. Ministério da Agricultura, Pecuária e Abastecimento. Instrução Normativa $\mathrm{n}^{\circ} 62$, de 29 de dezembro de 2011. Diário Oficial da União, 29 dez. 
2011. Seção 1.

BEHMER MLA. 1987. Tecnologia do leite: leite, queijo, manteiga, caseína, iogurte, sorvetes e instalações: produção, industrialização, análise. 15.ed. São Paulo: Nobel. 320p.

BUENO VFF et al. 2008. Contagem bacteriana total do leite: relação com a composição centesimal e período do ano no Estado de Goiás. Revista Brasileira de Ciência Veterinária 15: 40-44.

CAVALCANTI ERC et al. 2010. Avaliação microbiológica em ordenhadeira mecânica antes e após a adoção de procedimento orientado de higienização. Revista Brasileira de Ciência Veterinária 17: 3-6.

CORDIOLI E et al. 2009. Sistemas de Produção de Leite e Qualidade do Produto Final na Agricultura Familiar. Revista Brasileira de Agroecologia 4: 4493-4496.

CHAUHAN VPS \& HAYES JF. 1991. Genetic parameters for first lactation milk production and composition traits Holsteins using multivariate restricted maximum likelihood. Journal of Dairy Science 74: 603-610.

GUIDO ES et al. 2010. Uma abordagem da extensão universitária na melhoria da qualidade do leite na cadeia produtiva do município de Barbosa Ferraz (Paraná). Boletim do Centro de Pesquisa e Processamento de Alimentos 28: 303-312.

HORST JA. 2006. Impacto da refrigeração na contagem bacteriana do leite. IN: MESQUITA AJ et al. (Eds.). Perspectivas e avanços da qualidade do leite no Brasil. Goiânia: Talento. p.163-174.

MACHADO PF et al. 2000. Composição do leite de tanques de rebanhos brasileiros distribuídos segundo sua contagem de células somáticas. Revista Brasileira de Zootecnia 29: 1883-1886.

SANTOS MV \& FONSECA LFL. 2002. Composição e propriedades físico-químicas do leite. Curso on-line sobre monitoramento da qualidade do leite, módulo 1. Instituto Fernando Costa - Milkpoint.

SANTOS MV 2007. Boas Práticas de Produção associadas à higiene de ordenha e qualidade do leite. In: CARVALHO MP \& SANTOS MV (Org.). O Brasil e a nova era do mercado do leite- Compreender para competir. 1.ed. Piracicaba: Agripoint Ltda. p.135-154.

SANTOS MV \& FONSECA LFL. 2007. Estratégias para controle de mastite e melhoria da qualidade do leite. Barueri: Manole. 314p.

SILVA FAS \& AZEVEDO CAV. 2009. Principal Components Analysis in the Software Assistat-Statistical Attendance. In: 7 World Congress On Computers In Agriculture. Reno-NV-USA: American Society of Agricultural and Biological Engineers.

SUTTON JD. 1989. Altering milk composition by feeding. Journal of Dairy Science 72: 2801-2814.

TAFFAREL LE et al. 2013. Contagem bacteriana total do leite em diferentes sistemas de ordenha e de resfriamento. Arquivos do Instituto Biológico 80: 7-11.

VAN SLYKE LL. 1894. Investigation relating to the manufacture of cheese. New York Agricultural Experiment Station v. 65.

VANCE ER et al. 2012. Food intake, milk production, and tissue changes of Holstein-Friesian and Jersey x HolsteinFriesian dairy cows within a medium-input grazing system and a high-input total confinement system. Journal of Dairy Science 95: 1527-1544.

VIANA KF et al. 2010. Comparação da contagem de células somáticas em leite cru por quatro métodos de coloração. Acta Veterinaria Brasilica 4: 59-63.

WHITE SL et al. 2002. Milk production and economic measures in confinement or pasture systems using seasonally calved Holstein and Jersey cows. Journal of Dairy Science 85: 95-104.

ZAFALON LF et al. 2008. Boas práticas de ordenha. São Carlos: Embrapa Pecuária Sudeste. Disponível em http:// central3.to.gov.br/arquivo/228631/. Acesso em: 04 jul. 2015. 